\title{
Two Echelon Supply Chain with Vendor Managed Inventory and Revenue Sharing Contract under Shortage Gaming Scenario
}

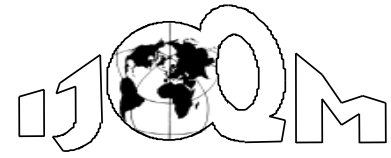

DOI: $10.46970 / 2020.26 .4 .2$

Volume 26, Number 4

December 2020, pp. 255-283

\author{
Reena Jain \\ Chandra K. Jaggi \\ Mona Verma \\ University of Delhi \\ (reenajain1910@yahoo.com) \\ (ckjaggi@yahoo.com) \\ (monavermag@sscbsdu.ac.in)
}

This paper explores the idea of Vendor Managed Inventory (VMI) for curbing the bullwhip effect in a single vendor - multiple buyers supply chain under a revenue-sharing contract. The capacity-constrained vendor in a monopolistic environment allocates supply among buyers. Further, price-sensitive demand and VMI bound buyers to follow a revenue-sharing contract. Limited supply and price sensitive demand induces bullwhip effect. In such a scenario, an attempt has been made to develop NLPP models to calculate optimal wholesale price and buyers selling price to optimize the supply chain profit. The aforesaid model is compared with a less coordinated model to show the impact of revenue sharing contract on the bullwhip effect.

Keywords: Bullwhip Effect, Shortage Gaming, Vendor Managed Inventory (VMI), Revenue Sharing Contract, Price Sensitive Demand

\section{Introduction}

A common problem with which nowadays supply chain is dealing with is the bullwhip effect. It is defined as a supply chain phenomenon of amplification of demand from the lower echelon of the supply chain to the higher echelon of the supply chain, (Forrester, 1961). This phenomenon is highly responsible for hampering the efficiency and effectiveness of the supply chain and causes a reduction in measures of performance of the supply chain. This issue of efficiency and performance measures can be managed well through legitimate data sharing, correspondence, and coordination between its different stages. Instances of communitarian and helpful understandings come in numerous structures and by numerous names, including Continuous Replenishment (CR), Vendor Managed Inventory (VMI), Collaborative Planning, Forecasting, and Replenishment (CPFR), and Information Sharing Programs (ISP). The mutual objective of every level of these projects is to increase the value of the supply chain by reducing the bullwhip effect. In the present study, VMI and revenue sharing is used as an idea for correspondence and coordination between the stages of the supply chain and make the information sharing fast and accurate.

Further, every business firm uses forecasting techniques to expect future demand at each echelon of the supply chain. As the number of echelons in the supply chain increases, the number of forecasting attempts and hence forecasting errors increases. 
This in turn causes the bullwhip effect. It can be mitigated either by reducing the number of echelons or by sharing Point of Sale (POS) demand information with an upstream member of the supply chain. In the present study, VMI serves the purpose by sharing POS demand information directly with the vendor.

In the case of VMI, the vendor manages inventory at the buyer's end. The display of product, monitoring of inventory level, time, and quantity of replenishment everything is under the direct control of the vendor. It helps the vendor to keep tight control over the display of products at retail stores, which distributes the product efficiently. Moreover, since the vendor gets to see actual sales data, the demand information reaches to higher echelon without any distortion and hence reduces the bullwhip effect. In the literature, the lead time is mentioned as one of the important factors to enhance the bullwhip effect, (Agrawal, et al., 2009) which also gets reduced in the case of VMI. Therefore, VMI is getting popular nowadays as it benefits both the parties, i.e., buyers as well as vendor. The buyer is benefitted as he can improve his fill rate and hence profit share without taking tension of inventory management, while the vendor can enjoy the benefits of better production planning by having direct access to the downstream market information. In most of the examples of VMI, the vendor dominates the buyer and do business as per his conditions such as Campbell Soup Company, still, examples exist where one of the buyers acts as a leader and negotiates on wholesale price on his terms. Wal-Mart is one of such buyers.

Motivated by the advantages of VMI in managing the bullwhip effect and increasing the value of the supply chain, we are encouraged to conduct the present study. The rest of the paper is organized as follows: Literature review along with assumptions and notations are discussed in section 2. The problem is formulated in section 3 and supported by numerical analysis in section 4. Managerial insight is presented in section 5 followed by conclusions and suggestions for future research in section 6.

\section{Literature Review}

Ample literature had been studied regarding the bullwhip effect, rationing, and VMI. The bullwhip effect mainly includes causes and quantification and rationing usually discusses the allocation mechanism. The concept of the bullwhip effect was introduced more than half-century ago by Forrester (1961). It is termed as Forrester effect, after the name of the discoverer. Later, Lee et al. (1997 (a)) defined it as the bullwhip effect. They categorized the causes of the bullwhip effect under four heads, viz. demand signal processing, order batching, shortage gaming, and price variation. Lee et al. (1997 (b)) proved that variation in demand at higher echelon increases when buyers optimize orders, which give birth to the bullwhip effect. They demonstrated that allocation capacity in proportion to orders induces strategic behavior. The impact of information sharing was explained by Chen et al. (2000) and Dejonckheere et al. (2004). As per their observations, variance amplification at the highest level i.e., at the fifth level (according to supply chain considered) can be reduced up to 50 percent by information sharing. Chatfield et al. (2004) proved that the bullwhip effect is directly proportional to lead time and as lead time decreases bullwhip effect also decreases. Recently, Tai et al. (2019) measured the bullwhip effect analytically in a simple two-stage supply chain with one supplier and one 
retailer. They proved that if the price is not considered then the bullwhip effect can be weaker or stronger under some conditions.

Many researchers worked on allocation policy under a different scenario. Cachon \& Lariviere (1999(a)) compared three allocation mechanisms under capacity constraint. They derived the method to find Nash equilibrium in capacity allocation game for linear and proportional allocation. Cachon \& Lariviere (1999(b)) further claimed that a manipulable mechanism is always preferable over truth inducing mechanism in case of rationing. Kaplan (1969) discussed the use of reserve levels, i.e. the level of stock at which to stop issuing in response to lower priority demand. An algorithm which calculates optimum reserve levels is developed. Deshpande and Schwarz (2002) used a mechanism-design approach to obtain the optimal capacityallocation rule and pricing mechanism for the vendor. Through his article optimal level of vendor's capacity and practical ways of implementing the optimal allocation policy to reduce transaction costs were determined. Jaggi et al. (2010) introduced a reallocation mechanism in the existing allocation policy to create dual profit by reducing inventory at the vendor's end and increasing PFR at the buyer's end. Further, Jaggi et al (2018 (a)) introduced a new allocation algorithm to deal with two major drawbacks of existing algorithms. The proposed algorithm was free from the decision variable for how many buyer's allocation would be done with priority and reallocation was not required. Moreover, unlike Cachon \& Lariviere (1999(b)) they claimed that truth inducing mechanism helps in reducing the bullwhip effect. Further, in the same year, Jaggi et al (2018 (b)) introduced demonetization as a new cause of bullwhip effect. It is not a routine scenario but definitely a cause not explored in literature till then.

Disney and Towill (2003) compared the impact on the bullwhip effect in VMI supply chain and traditional serially-linked supply chain. Through this paper, they had proved that with VMI implementation, out of four existing causes, Lee et al. (1997 (a)) rationing and order batching can completely be eliminated. They also claimed that due to price variation bullwhip effect can be significantly reduced. Daugherty et al. (1999) proved that VMI helps in improving service levels, reduces lead time and risks of inventory stock-outs. Darwish \& Odah (2010) developed a model for a single-vendor multi-buyer supply chain under VMI with a penalty clause on the vendor that the inventory at the buyer's place would never exceed his capacity.

Some important literature related to price-sensitive demand and premium payment scheme is also covered. Adnan \& Ozelkan (2020) identified the conditions for the occurrence of the bullwhip effect in pricing in case of a revenue-sharing contract. For this purpose, they considered deterministic and stochastic demand structures. Recently, Jain et al (2020) explained the FDA as a platform which mitigates bullwhip effect in presence of price variation. Kim et al. (2011) developed pricing and ordering policies for a single vendor and multiple buyers under a price-sensitive environment. Recently Chen et al. (2019) explored the time-varying and pricesensitive demand model for evaluating optimal pricing and replenishment policy under stock dependent demand for deteriorating items. Ozelkan \& Cakanyildirim (2018) studied the reverse bullwhip effect in case of pricing. Yang \& Yang (2007) discussed the premium payment scheme in a capacity-constrained supply chain along 
with a penalty clause. They claimed that the adoption of this practice can lure the supplier to build a bigger capacity. The present paper extends their idea in a more practical scenario. Here, price-sensitive demand and revenue sharing contract is also taken into account. Moreover, in the present paper whole modeling is done in the VMI system to reduce the bullwhip effect. In the present study, multiple buyers facing price-sensitive demand are considered. The demand at the buyer's end is high, whereas supply at the vendor's end is limited. To meet the demand, the idea of premium payment is introduced. The buyers are abiding by a revenue-sharing contract due to VMI.

The motivation behind the present study revolves around the advantages of VMI to fight with the losses due to the bullwhip effect. The models are developed under the following assumptions:

\section{Assumptions}

- The vendor has limited capacity and has a monopoly over the market.

- Demand at the buyer's end is price sensitive.

- Buyers are also enjoying a monopoly in their vicinity because of geographical location.

- Profit is shared between vendor and buyer in some predetermined ratio in case of a revenue-sharing contract.

- Since inventory is managed by the vendor, stock out (if any) is also borne by the vendor.

- Buyers are paying premium payments to the vendor for managing the scarcity of supply (if required). The numbers of units for which buyers are paying premium are called premium units.

- The vendor is liable to pay penalty for the non-fulfillment of demand for premium units. The amount of penalty paid per unit would be greater than the amount of premium received per unit.

- The vendor is replenishing the inventory of each buyer simultaneously in different batch sizes.

\section{Notation}

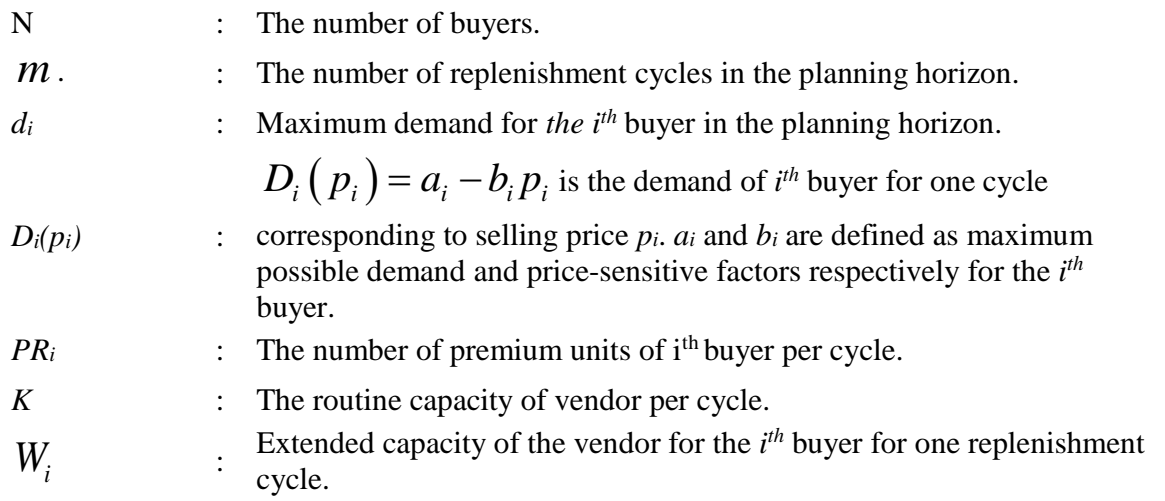




$$
\begin{aligned}
& W=\sum_{i=1}^{N} W_{i} \quad: \quad \text { Extended capacity of the vendor for one replenishment cycle. } \\
& h_{R i} \quad: \text { Inventory carrying cost per unit per cycle for the } i^{\text {th }} \text { buyer. } \\
& h_{s} \quad: \text { Inventory carrying cost per unit per cycle for the Vendor. } \\
& \mathrm{S}_{\mathrm{i}} \quad: \text { Ordering cost of the } i^{\text {th }} \text { buyer. } \\
& \text { S : Setup cost per order for the vendor. } \\
& \pi_{r i} \quad: \text { Profit of } i^{\text {th }} \text { buyer/cycle. } \\
& \pi_{S} \quad: \text { Profit of the vendor/cycle. } \\
& C_{p} \quad: \text { The contract price between vendor and buyer for the unit item. } \\
& C \quad \text { : The unit cost price of the vendor for routine production. } \\
& C_{W} \quad \text { The unit cost price of the vendor in case of extended capacity, } \\
& C_{S P} \quad: \quad \text { Vendor's selling price per unit in absence of revenue sharing contract. } \\
& \theta_{i} \epsilon(0,1) \quad \text {. The prefixed fraction of profit taken by the vendor from the sales of an } \\
& i^{\text {th }} \text { buyer. } \\
& \left(1-\theta_{i}\right) \epsilon(0,1): \quad \text { The prefixed fraction of profit is taken by an } i^{\text {th }} \text { the buyer from his } \\
& \text { sales in case of revenue sharing. } \\
& \alpha \in(0,1) \quad \text { : The fraction of } C_{p} \text {, paid by a buyer to the vendor as a premium amount } \\
& \text { per unit. } \\
& \beta \epsilon(0,1) \quad: \begin{array}{l}
\text { The fraction of } C_{p} \text {, paid by the vendor to the buyer as a pen } \\
\text { non-fulfillment of demand of premium units, where } \beta>\alpha .
\end{array}
\end{aligned}
$$

\section{Model Description and Formulation}

In the present study, a supply chain model in a monopolistic environment with a VMI system consisting of a single vendor and $N$ buyers has been considered. The vendor has limited capacity, which can further be extended on incurring additional costs. This additional cost is justified either because of overtime production or outsourcing. The demand generated at the buyer's end is price sensitive with demand function, $D_{i}\left(p_{i}\right)=a_{i}-b_{i} p_{i}$. The total demand of all the buyers is more than the vendor's capacity. Hence, the vendor has two options: (1) Vendor distributes supply according to the demand calculated from the demand function. The optimal selling price of buyers calculated through the model would be substituted to get the optimal demand. In this case, since demand is determined from the selling price of buyers therefore selling price of buyers would be an independent variable and demand would be a dependent variable. (2) The vendor will allocate his supply using a predefined allocation mechanism, Iterative Proportional Algorithm (IPA) (Jaggi et al., 2018(a)) and the selling price of the buyer will be evaluated from the demand function. Here, demand would be the independent variable and the selling price of the buyers would be the dependent variable. Further, the model can be explored in two scenarios. In the first scenario, under the VMI model, a revenue-sharing contract between vendor and buyer and a contract price is considered. The Supply chain model is jointly optimized to calculate the contract price between vendor and buyers, 
selling price of buyers, and premium units of buyers. The vendor offers his product to the buyers at this optimal contract price, i.e. no profit no loss for him and he gains profit due to the revenue-sharing contract between him and buyers. Since all the profit is generated by the sales of buyers only. The responsibilities and ratio of revenue for each party are priories fixed and followed by each of them. Profit generated by the sales of the $i^{\text {th }}$ buyer would be shared between the vendor and $i^{\text {th }}$ buyer in the ratio $\theta_{i}$ and $\left(1-\theta_{i}\right)$ respectively $\left(0<\theta_{i}<1\right)$. This ratio can be different for each buyer as it depends upon many factors such as the amount of business provided by a particular buyer, the goodwill and the location of the store etc. It is a fully coordinated and transparent model. In the second scenario under the VMI model, there is no revenue-sharing contract, but the selling price of the vendor is considered. Since the vendor is a leader, he sets his selling price to maximize his profit. Here each member of the supply chain is deciding his parameters in isolation in his interest. Each member is calculating his individual profit and total profit is obtained just by adding their individual profits. This model is comparatively less coordinated and less transparent. These two scenarios would be discussed under a 'completely coordinated VMI scenario' and 'less coordinated VMI scenario'.

Further, since the total demand of all the buyers is more than the vendor's capacity, the supply chain may suffer from shortages. Due to VMI, buyers are free from managing these shortages; still, shortages would reduce the buyer's profit by reducing their sales. Thus, in fear of curtailment of supply, buyers decided to pay premium payment to the vendor so that they can motivate him to increase his production capacity. Since increased sales would increase the vendor's profit also, therefore he agrees to extend his existing capacity for meeting the demand of premium units. Furthermore, the vendor is abiding by a penalty clause that if he fails to meet the demand of premium units, he is liable to pay penalty.

The demand for a complete planning horizon would be satisfied in $m$ number of cycles. It would reduce the amount of inventory in one place and hence would reduce the inventory carrying cost, but the placing of more orders would increase ordering and set up cost. Hence, the optimal number of orders is calculated by a tradeoff between total ordering cost and total inventory holding cost for a planning horizon. The orders of all buyers are replenished at the same time but in different sizes. The optimal number of cycles for the planning horizon is calculated as follows

Total ordering cost $=\left(\sum_{i=1}^{N} S_{i}+S\right) m$

Total inventory holding cost $=\sum_{i=1}^{N} \frac{d_{i}\left(h_{R i}+h_{S}\right)}{2 m}$

Total Cost $=T C(m)=\left(\sum_{i=1}^{N} S_{i}+S\right) m+\sum_{i=1}^{N} \frac{d_{i}\left(h_{R i+} h_{S}\right)}{2 m}$ 
Let $\left(\sum_{i=1}^{N} S_{i}+S\right)=S^{*}$

$T C(m)$ is a function of $m$, which is a discrete variable. For calculating the optimal value of $m$, the condition of the discrete variable on $m$ is relaxed and would be reconsidered later.

The necessary and sufficient condition for optimality of $m$ is $T C^{\prime}(m)=0$ and $T C^{\prime \prime}(m)>0$

$T C^{\prime}(m)=S^{*}-\sum_{i=1}^{N} \frac{d_{i}\left(h_{R i}+h_{S}\right)}{2 m^{2}}=0$

$m=\sqrt{\sum_{i=1}^{N} \frac{d_{i}\left(h_{R i}+h_{S}\right)}{2 S^{*}}}$

$T C^{\prime \prime}(m)=\sum_{i=1}^{N} \frac{d_{i}\left(h_{R i}+h_{S}\right)}{m^{3}}>0$

Hence, $m$ obtained by equation (2) will minimize $T C(m)$.

As $m$ represents the number of orders, hence $m$ must be an integer. Therefore, an integer value of $m$ obtained from equation (2) will be an optimal value. Otherwise, evaluate $m$ as follows:

Step 1: Calculate $T C(m)$ in equation (1) by substituting the value of $m$ calculated from equation (2) and equation (3).

$$
m=\left[\sqrt{\sum_{i=1}^{N} \frac{d_{i}\left(h_{R i}+h_{S}\right)}{2 S^{*}}}\right]+1
$$

Where [.] represent the greatest integer function.

Step 2: Select the $m$ corresponding to which $T C(m)$ is minimum Now, the vendor is receiving information from each buyer in terms of orders i.e. $d_{i}$ by the $i^{\text {th }}$ buyer for the complete planning horizon. This order is fulfilled in $m$ cycles, given by equation (2) or equation (3). Hence, the maximum possible demand for any replenishment cycle for the $i^{\text {th }}$ buyer would be

$$
a_{i}=\frac{d_{i}}{m}
$$


And the corresponding demand function would be $D_{i}\left(p_{i}\right)=a_{i}-b_{i} p_{i}$.

For the completely coordinated scenario, an attempt has been made to develop mathematical models to calculate the three vital parameters i.e. contract price, buyer's selling price, and the number of premium units to be produced on extended capacity in presence of price-sensitive demand, VMI, and revenue sharing contract. For the less coordinated scenario, individual problems for the vendor and buyers are formulated. By comparing these two scenarios, it has been shown that a revenuesharing contract makes the model more coordinated and hence reduces the bullwhip effect. Further, for the present study, IPA (Jaggi et al., 2018 (a)) is used as an allocation policy (wherever rationing is done) since it curbs the bullwhip effect to the maximum extent. To discuss the aforementioned scenarios, the problem is divided into two cases, which are further divided into sub cases. The framework of the model has been summarized with the help of Figure1.

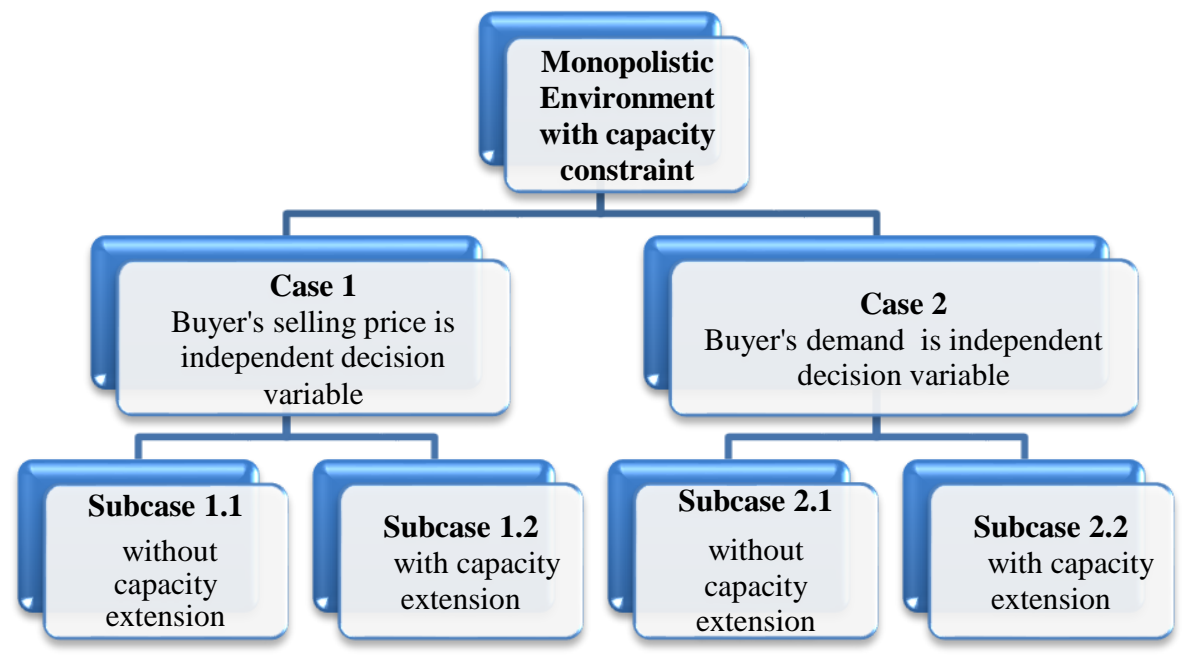

Figure 1 Model Framework

For each sub case, a separate model is developed to calculate the profit of each buyer and vendor under a completely coordinated as well as less coordinated scenario.

\section{Case 1: Buyer's Selling Price is an Independent Decision Variable}

In this case, the model is formulated to calculate the optimal selling price of each buyer. Then this optimal price is substituted in the demand function of each buyer to get his optimal demand. Now, the vendor's capacity is allocated according to this optimal demand. This case doesn't involve any rationing. It is further divided into two sub cases. 


\section{Sub-case 1.1: Without the Capacity Extension}

Here the model is developed under the constraint that the vendor can't distribute more than his routine capacity as he can't extend his existing capacity. The limited capacity of the vendor is allocated according to the demand calculated from the optimal price. In the case of a completely coordinated VMI scenario, due to contract price, all the profit is generated by the sales of buyers only. Hence, the total supply chain profit is composed of the profit of all the buyers. The profit of each buyer is determined as the product of sales and unit profit. Hence, the total supply chain profit function would be an objective function of the nonlinear programming problem

Net profit of $i^{\text {th }}$ buyer $=$ per unit profit $*$ demand

$$
\begin{aligned}
& \forall i=1 \ldots N \\
& \forall i=1 \ldots N .
\end{aligned}
$$$$
\pi_{r i}\left(p_{i}, C_{p}\right)=\left(p_{i}-C_{p}\right)\left(a_{i}-b_{i} p_{i}\right) \text {. }
$$

Hence, the total supply chain profit is:

$$
\sum_{i=1}^{N} \pi_{r i}\left(p_{1}, p_{2}, \ldots, p_{N}, C_{p}\right)=\sum_{i=1}^{N}\left(\left(p_{i}-C_{p}\right)\left(a_{i}-b_{i} p_{i}\right)\right)
$$

The NLPP is formulated under some constraints, which can be explained as:

Unit contract price $\geq$ vendor's unit production cost + unit holding cost + unit ordering cost

$$
\begin{aligned}
& \Rightarrow C_{p} \geq C+h^{*}+\frac{S^{*}}{K} \quad, \text { where } h^{*}=\frac{h_{s} * K+\sum_{i=1}^{N}\left(h_{R i} *\left(a_{i}-b_{i} p_{i}\right)\right)}{2 K} \text { and } \\
& S^{*}=S+\sum_{i=1}^{N} S_{i}
\end{aligned}
$$

The total demand of all the buyers $\leq$ Total capacity of vendor

$$
\Rightarrow \sum_{i=1}^{N}\left(a_{i}-b_{i} p_{i}\right) \leq K
$$

The unit selling price of each buyer must be greater than the contract price

$$
\Rightarrow p_{i} \geq C_{p} \quad \forall i=1 \ldots N
$$

The demand of each buyer must be a positive integer.

$$
\Rightarrow a_{i}-b_{i} p_{i} \geq 0 \quad \text { andinteger } \quad \forall i=1 \ldots . . N
$$

Hence NLPP, P1for completely coordinated VMI scenario can be written as 
$\operatorname{Max} \sum_{i=1}^{N} \pi_{r i}\left(p_{1}, p_{2}, \ldots, p_{N}, C_{p}\right)=\sum_{i=1}^{N}\left(\left(p_{i}-C_{p}\right)\left(a_{i}-b_{i} p_{i}\right)\right)$

subject to .

$\Rightarrow C_{p} \geq C+h^{*}+\frac{S^{*}}{K} \quad$, where $h^{*}=\frac{h_{s} * K+\sum_{i=1}^{N}\left(h_{R i} *\left(a_{i}-b_{i} p_{i}\right)\right)}{2 K} \quad$ and $S^{*}=S+\sum_{i=1}^{N} S_{i}$

$\sum_{i=1}^{N}\left(a_{i}-b_{i} p_{i}\right) \leq K$

$p_{i} \geq C_{p} \quad \forall i=1 \ldots . . N$

$a_{i}-b_{i} p_{i} \geq 0 \quad$ and integer $\quad \forall i=1 \ldots . . N$

P1 consists of $N+1$ decision variable namely $\left(p_{1}, p_{2}, \ldots, p_{N}, C_{p}\right)$. The necessary and sufficient condition for the concavity of P1 is proved in Appendix 1.Contract price and optimal selling price of buyers are evaluated by solving P1 and then profit is calculated and distributed among the vendor and buyers according to predetermined proportion, $\theta_{i}$ and $\left(1-\theta_{i}\right)$ according to equation (6) and (7) respectively.

Vendor's Profit $\left(\pi_{S}\right)=\sum_{i=1}^{N}\left(\pi_{r i}\right) \theta_{i}=\sum_{i=1}^{N}\left(\left(p_{i}-C_{p}\right)\left(a_{i}-b_{i} p_{i}\right) \theta_{i}\right)$

$i^{\text {th }}$ Buyer's effective profit $=\left(1-\theta_{i}\right) \pi_{r i}=\left(1-\theta_{i}\right)\left(p_{i}-C_{p}\right)\left(a_{i}-b_{i} p_{i}\right)$

$\forall i=1 \ldots N$

The corresponding NLPP, $P 1$. For less coordinated VMI scenario can be written by replacing $C_{p}$ with $C_{S P}$ in P1. The vendor's problem and the buyer's problem for this scenario is given as follows:

Vendor's Problem

$\operatorname{Max} \pi_{S}\left(C_{S P}\right)=\left(C_{S P}-h^{*}-C\right) K-S^{*}$

Subject to 
$C_{S P} \geq C+h^{*}+\frac{S^{*}}{K} \quad$, where $\quad h^{*}=\frac{h_{s}^{*} K+\sum_{i=1}^{N}\left(h_{R i} *\left(a_{i}-b_{i} p_{i}\right)\right)}{2 K} \quad$ and $S^{*}=S+\sum_{i=1}^{N} S_{i}$

Now, since $C_{S P}$ has no upper bound, therefore, the vendor's problem is unbounded. This nature of the vendor's problem will remain consistent independent of the sub case.

\section{Buyer's Problem}

$$
\operatorname{Max} \sum_{i=1}^{N} \pi_{r i}\left(p_{1}, p_{2}, \ldots, p_{N}\right)=\sum_{i=1}^{N}\left(\left(p_{i}-C_{S P}\right)\left(a_{i}-b_{i} p_{i}\right)\right)
$$

Subject to

$$
\begin{aligned}
& \Rightarrow C_{S P} \geq C+h^{*}+\frac{S^{*}}{K} \quad, \text { where } h^{*}=\frac{h_{s}^{*} K+\sum_{i=1}^{N}\left(h_{R i} *\left(a_{i}-b_{i} p_{i}\right)\right)}{2 K} \quad \text { and } \\
& S^{*}=S+\sum_{i=1}^{N} S_{i}
\end{aligned}
$$$$
\sum_{i=1}^{N}\left(a_{i}-b_{i} p_{i}\right) \leq K
$$

$$
\begin{array}{lc}
p_{i} \geq C_{S P} & \forall i=1 \ldots N \\
a_{i}-b_{i} p_{i} \geq 0 \quad \text { and integer } & \forall i=1 \ldots N
\end{array}
$$

\section{Sub-case 1.2: With Capacity Extension}

In this sub case, the vendor could extend his existing capacity on account of premium payment received from the buyers. The total capacity to be distributed among buyers would be the sum of routine capacity and extended capacity. Here, the penalty is also associated with premium payment. If the vendor fails to meet the demand of premium units for which he had received a premium, he is liable to pay a penalty. In this situation along with selling prices, the premium units of each buyer will also be a decision variable. In the case of a completely coordinated VMI scenario, $\mathrm{Cp}$ will also be a decision variable. Hence, the total number of decision variables would be $2 N+1$, i.e. $\left(p_{1}, p_{2}, \ldots p_{N}, C_{p} P R_{1}, P R_{2}, \ldots, P R_{N}\right)$. The total supply chain profit is composed of three terms, i.e. profit from sales, the premium 
paid by each buyer to the vendor, and the penalty paid by the vendor to each buyer. The total supply chain profit would be the objective function of the problem.

Net profit of $i^{\text {th }}$ buyer $=$ per unit profit $*$ demand - premium payment paid + penalty received

$$
\begin{aligned}
& \forall i=1 \ldots . . N \\
& \Rightarrow \pi_{r i}\left(p_{i}, C_{p}, P R_{i}\right)=\left(p_{i}-C_{p}\right) D_{i}\left(p_{i}\right)-\alpha C_{p} P R_{i}+\beta C_{p}\left(P R_{i}-W_{i}\right) \quad \forall i=1 \ldots N
\end{aligned}
$$

Hence the total supply chain profit is

$$
\sum_{i=1}^{N} \pi_{r i}\left(p_{1}, p_{2}, \ldots \ldots p_{N}, C_{p} P R_{1}, P R_{2}, \ldots, P R_{N}\right)=\sum_{i=1}^{N}\left(\left(p_{i}-C_{p}\right) D_{i}\left(p_{i}\right)-\alpha C_{p} P R_{i}\right)+\beta C_{p}\left(\sum_{i=1}^{N} P R_{i}-W\right)
$$

In this sub case, the vendor is doing production in two ways: routine production and production on extended capacity. Hence vendor's unit production cost is calculated as

Vendor's unit production cost $=$

total cost of routine production + total cost of the extended capacity total number of units produced

$\Rightarrow$ Vendor's unit production cost $=\frac{K C+C_{W} W}{K+W}$

Hence, NLPP P2 for a completely coordinated VMI scenario can be written as:

$$
\begin{aligned}
\operatorname{Max} \sum_{i=1}^{N} \pi_{r i}\left(p_{1}, p_{2}, \ldots \ldots p_{N}, C_{p} P R_{1}, P R_{2}, \ldots, P R_{N}\right)= & \sum_{i=1}^{N}\left(\left(p_{i}-C_{p}\right) D_{i}\left(p_{i}\right)-\alpha C_{p} P R_{i}\right) \\
& +\beta C_{p}\left(\sum_{i=1}^{N} P R_{i}-W\right)
\end{aligned}
$$

Subject to

$\Rightarrow C_{p} \geq \frac{K C+\left(C_{W}-\alpha C_{p}\right) W+S^{*}}{K+W}+h^{*}$

Where $h^{*}=\frac{h_{s} *(K+W)+\sum_{i=1}^{N}\left(h_{R i} D_{i}\left(p_{i}\right)\right)}{2(K+W)}$ and $S^{*}=S+\sum_{i=1}^{N} S_{i}$

$\sum_{i=1}^{N}\left(a_{i}-b_{i} p_{i}\right) \leq K+W$ 


$$
\begin{array}{lc}
W=\sum_{i=1}^{N} W_{i}=\sum_{i=1}^{N} P R_{i} & \\
p_{i} \geq C_{p} & \forall i=1 \ldots N \\
a_{i}-b_{i} p_{i} \geq 0 \text { and are integers } \quad \forall i=1 \ldots N \\
D_{i}\left(p_{i}\right) \geq 0, P R_{i} \geq 0 \text { and are integers } \quad \forall i=1 \ldots N
\end{array}
$$

The sufficient conditions for optimality of P2 are proved in Appendix 2. Vender's and buyer's profit proportions can be calculated as

Vendor's Profit $\left(\pi_{S}\right)=\sum_{i=1}^{N}\left(\pi_{r i}\right) \theta_{i}=\sum_{i=1}^{N}\left(\left(p_{i}-C_{p}\right) D_{i}\left(p_{i}\right)-\alpha C_{p} P R_{i}\right) \theta_{i}$

$i^{\text {th }}$ Buyer's effective profit $=$

$$
\left(1-\theta_{i}\right) \pi_{r i}=\left(1-\theta_{i}\right)\left(\left(p_{i}-C_{p}\right) D_{i}\left(p_{i}\right)-\alpha C_{p} P R_{i}\right) \forall i=1 \ldots N
$$

The corresponding NLPP, $P 2$ for less coordinated VMI scenario, can be written as follows:

\section{Vendor's Problem}

$$
\operatorname{Max} \pi_{S}\left(C_{S P}\right)=\left(C_{S P}-h^{*}\right)(K+W)-K C-\left(C_{W}-\alpha C_{S P}\right) W-S^{*}
$$

Subject to

$$
C_{S P} \geq \frac{K C+\left(C_{W}-\alpha C_{S P}\right) W+S^{*}}{K+W}+h^{*}
$$

Where $h^{*}=\frac{h_{s} *(K+W)+\sum_{i=1}^{N}\left(h_{R i} D_{i}\left(p_{i}\right)\right)}{2(K+W)}$ and $S^{*}=S+\sum_{i=1}^{N} S_{i}$

\section{Buyer's Problem}

$$
\begin{aligned}
\operatorname{Max} \sum_{i=1}^{N} \pi_{r i}\left(p_{1}, p_{2}, \ldots \ldots p_{N}, P R_{1}, P R_{2}, \ldots, P R_{N}\right) & =\sum_{i=1}^{N}\left(\left(p_{i}-C_{S P}\right) D_{i}\left(p_{i}\right)-\alpha C_{S P} P R_{i}\right) \\
& +\beta C_{S P}\left(\sum_{i=1}^{N} P R_{i}-W\right)
\end{aligned}
$$

Subject to

$$
\Rightarrow C_{S P} \geq \frac{K C+\left(C_{W}-\alpha C_{S P}\right) W+S^{*}}{K+W}+h^{*}
$$


Where $h^{*}=\frac{h_{s} *(K+W)+\sum_{i=1}^{N}\left(h_{R i} D_{i}\left(p_{i}\right)\right)}{2(K+W)}$ and $S^{*}=S+\sum_{i=1}^{N} S_{i}$

$\sum_{i=1}^{N}\left(a_{i}-b_{i} p_{i}\right) \leq K+W$

$W=\sum_{i=1}^{N} W_{i}=\sum_{i=1}^{N} P R_{i}$

$p_{i} \geq C_{S P} \quad \forall i=1 \ldots . . N$

$a_{i}-b_{i} p_{i} \geq 0$ and integer $\quad \forall i=1 \ldots N \quad P 2$

$D_{i}\left(p_{i}\right) \geq 0, P R_{i} \geq 0$ and are integers $\quad \forall i=1 \ldots . . N$

\section{Case 2: Demand is an Independent Decision Variable}

In this case vendor's capacity is allocated according to the rationing algorithm (IPA) and then the buyer's selling price would be calculated from the demand function. It is further divided into two subcases depending upon whether capacity is extended or not.

\section{Sub-case 2.1: Without Capacity Extension}

The demand would be allocated using the rationing algorithm IPA. In this case, demand is not a function of selling price hence, $D_{i}\left(p_{i}\right)=D_{i}$. This demand would be used to calculate the selling price because demand and price are interdependent due to price-sensitive demand. In a completely coordinated VMI model, the total supply chain profit would be the sum of profits generated by the sales of all the buyers. To calculate the total supply chain profit in this scenario, the linear programming problem is developed.

Net profit of $i^{\text {th }}$ buyer $=$ per unit profit $*$ demand $\quad \forall i=1 \ldots . N$

$\Rightarrow \pi_{r i}\left(C_{p}\right)=\left(p_{i}-C_{p}\right)\left(D_{i}\right) \forall i=1 \ldots N$

Hence the total supply chain profit is

$\sum_{i=1}^{N} \pi_{r i}\left(C_{p}\right)=\sum_{i=1}^{N}\left(\left(p_{i}-C_{p}\right) D_{i}\right)$

Hence LPP P3, in a completely coordinated VMI scenario can be written as 


$$
\operatorname{Max} \sum_{i=1}^{N} \pi_{r i}\left(C_{p}\right)=\sum_{i=1}^{N}\left(\left(p_{i}-C_{p}\right) D_{i}\right)
$$

Subject to

$$
\begin{aligned}
& C_{p} \geq C+\frac{S^{*}}{K}+h^{*} \text { whereh }^{*}=\frac{h_{s} \sum_{i=1}^{N} D_{i}+\sum_{i=1}^{N}\left(h_{R i} D_{i}\right)}{2 * \sum_{i=1}^{N} D_{i}} \text { and } S^{*}=S+\sum_{i=1}^{N} S_{i} \\
& D_{i}=a_{i}-b_{i} p_{i} \quad \forall i=1 \ldots N \\
& \sum_{i=1}^{N}\left(a_{i}-b_{i} p_{i}\right) \leq K \\
& p_{i} \geq C_{p} \quad \forall i=1 \ldots N
\end{aligned}
$$

$a_{i}-b_{i} p_{i} \geq 0$ and are integers $\quad \forall i=1 \ldots N \quad$ P3

Since demand is calculated by IPA, buyer's selling prices $p_{i}$ can be calculated using fixed allocated demand, $D_{i}$. Therefore, in this sub case, there is only one decision variable i.e. contract price $C_{p}$, which is calculated using P3. It is a bounded linear programming problem, hence will always possess an optimal solution. Also, Vendor's Profit

$$
\left(\pi_{S}\right)=\sum_{i=1}^{N}\left(\pi_{r i}\right) \theta_{i}=\sum_{i=1}^{N}\left(\left(p_{i}-C_{p}\right) D_{i} \theta_{i}\right)
$$

$i^{t h}$ Buyer's effective profit $=\left(1-\theta_{i}\right) \pi_{r i}=\left(1-\theta_{i}\right)\left(p_{i}-C_{p}\right) D_{i} \forall i=1 \ldots N$

The corresponding LPP for less coordinated VMI scenario can be written by replacing $C_{p}$ with $C_{S p}$ in $\mathrm{P} 3$ same as sub case 1.1. This would represent only the buyer's problem. The vendor's problem would be same as $P 1$.

\section{Buyer's Problem}

$$
\operatorname{Max} \sum_{i=1}^{N} \pi_{r i}\left(C_{S P}\right)=\sum_{i=1}^{N}\left(\left(p_{i}-C_{S P}\right) D_{i}\right) \text {. }
$$

Subject to

$$
\begin{aligned}
& C_{S P} \geq C+\frac{S^{*}}{K}+h^{*} \text { whereh }^{*}=\frac{h_{s} \sum_{i=1}^{N} D_{i}+\sum_{i=1}^{N}\left(h_{R i} D_{i}\right)}{2 * \sum_{i=1}^{N} D_{i}} \text { and } S^{*}=S+\sum_{i=1}^{N} S_{i} \\
& \sum_{i=1}^{N}\left(a_{i}-b_{i} p_{i}\right) \leq K
\end{aligned}
$$


$p_{i} \geq C_{S P} \quad \forall i=1 \ldots . . N$

$a_{i}-b_{i} p_{i} \geq 0$ and are integers $\quad \forall i=1 \ldots . . N \quad P 2$.

\section{Sub-case 2.2: With Capacity Extension}

In this sub case, the vendor could extend his existing capacity on account of premium payment received from the buyers. Firstly, routine capacity would be allocated to the buyers as per IPA and then extended capacity would be distributed according to premium payment received. Now the total number of units distributed among buyers would be the sum of routine capacity and extended capacity. The number of premium units for each buyer is calculated through a mathematical model. In case of a completely coordinated VMI scenario, the mathematical model would consist of $2 \mathrm{~N}+1$, i.e. $\left(p_{1}, p_{2}, \ldots p_{N}, C_{p} P R_{1}, P R_{2}, \ldots, P R_{N}\right)$ decision variables.

The total supply chain profit is composed of three terms, i.e. profit from sales, the premium paid by each buyer to the vendor, and the penalty paid by the vendor to each buyer. The total supply chain profit can be expressed by the objective function of the following problem.

Net profit of $i^{\text {th }}$ buyer $=$ per unit profit $*$ demand - premium payment paid + penalty received $\forall i=1 \ldots . . N$

$\Rightarrow \pi_{r i}\left(p_{i}, C_{p} P R_{i}\right)=\left(p_{i}-C_{p}\right) D_{i}\left(p_{i}\right)-\alpha C_{p} P R_{i}+\beta C_{p}\left(P R_{i}-W_{i}\right) \forall i=1 \ldots . . N$

Hence the total supply chain profit is

$$
\begin{aligned}
\sum_{i=1}^{N} \pi_{r i}\left(p_{1}, p_{2}, \ldots \ldots p_{N}, C_{p} P R_{1}, P R_{2}, \ldots, P R_{N}\right) & =\sum_{i=1}^{N}\left(\left(p_{i}-C_{p}\right) D_{i}\left(p_{i}\right)-\alpha C_{p} P R_{i}\right) \\
& +\beta C_{p}\left(\sum_{i=1}^{N} P R_{i}-W\right)
\end{aligned}
$$

In this sub case, the vendor is doing production in two ways: routine production and production on extended capacity. Hence vendor's unit production cost is calculated as:

Vendor's unit production cost $=$

total cost of routine production + total cost of the extended capacity

total number of units produced

$\Rightarrow$ Vendor's unit production cost $=\frac{K C+C_{W} W}{K+W}$

Hence NLPP P4 for completely coordinated VMI scenario can be written as 


$$
\begin{aligned}
\operatorname{Max} \sum_{i=1}^{N} \pi_{r i}\left(p_{1}, p_{2}, \ldots \ldots p_{N}, C_{p}, P R_{1}, P R_{2}, \ldots, P R_{N}\right) & =\sum_{i=1}^{N}\left(\left(p_{i}-C_{p}\right) D_{i}\left(p_{i}\right)-\alpha C_{p} P R_{i}\right) \\
& +\beta C_{p}\left(\sum_{i=1}^{N} P R_{i}-W\right)
\end{aligned}
$$

Subject to

$$
\begin{gathered}
C_{p} \geq \frac{K C+\left(C_{W}-\alpha C_{p}\right) W+S^{*}}{K+W}+h^{*} \\
\text { Where } h^{*}=\frac{h_{s} *(K+W)+\sum_{i=1}^{N}\left(h_{R i} D_{i}\left(p_{i}\right)\right)}{2(K+W)} \text { and } S^{*}=S+\sum_{i=1}^{N} S_{i} \\
D_{i}\left(p_{i}\right)=a_{i}-b_{i} p_{i} \\
\sum_{i=1}^{N}\left(a_{i}-b_{i} p_{i}\right) \leq K+W \\
a_{i}-b_{i} p_{i} \geq 0 \\
W=\sum_{i=1}^{N} P R_{i} \\
p_{i} \geq C_{p} \\
P R_{i} \geq 0 \text { and are integers } \quad \forall i=1 \ldots N
\end{gathered}
$$

P4 is a nonlinear integer programming problem. The sufficient conditions for optimality of P4 are proved in Appendix 3. Vendor's and buyer's profit proportions can be calculated as follows

Vendor's profit $\left(\pi_{S}\right)=\sum_{i=1}^{N}\left(\pi_{r i}\right) \theta_{i}=\sum_{i=1}^{N}\left(\left(p_{i}-C_{p}\right) D_{i}\left(p_{i}\right)-\alpha C_{p} P R_{i}\right) \theta_{i}$

$i^{t h}$ Buyer's effective profit $=\left(1-\theta_{i}\right) \pi_{r i}=\left(1-\theta_{i}\right)\left(\left(p_{i}-C_{p}\right) D_{i}\left(p_{i}\right)-\alpha C_{p} P R_{i}\right)$ $\forall i=1 \ldots N$

The corresponding NLPP for less coordinated VMI scenario can be written by replacing $C_{p}$ with $C_{S p}$ in $\mathrm{P} 4$ same as sub case 1.1 . This would represent only the buyer's problem. The Vendor's problem would be same as that mentioned in $P 2$. 


\section{Buyer's problem}

$$
\begin{aligned}
\operatorname{Max} \sum_{i=1}^{N} \pi_{r i}\left(p_{1}, p_{2}, \ldots \ldots p_{N}, P R_{1}, P R_{2}, \ldots, P R_{N}\right) & =\sum_{i=1}^{N}\left(\left(p_{i}-C_{S P}\right) D_{i}\left(p_{i}\right)-\alpha C_{S P} P R_{i}\right) \\
& +\beta C_{S P}\left(\sum_{i=1}^{N} P R_{i}-W\right)
\end{aligned}
$$

Subject to

$$
C_{S P} \geq \frac{K C+\left(C_{W}-\alpha C_{S P}\right) W+S^{*}}{K+W}+h^{*}
$$

Where $h^{*}=\frac{h_{s}^{*}(K+W)+\sum_{i=1}^{N}\left(h_{R i} D_{i}\left(p_{i}\right)\right)}{2(K+W)}$ and $S^{*}=S+\sum_{i=1}^{N} S_{i}$

$$
\begin{array}{ll}
D_{i}\left(p_{i}\right)=a_{i}-b_{i} p_{i} & \forall i=1 \ldots N \\
\sum_{i=1}^{N}\left(a_{i}-b_{i} p_{i}\right) \leq K+W & \\
a_{i}-b_{i} p_{i} \geq 0 & \forall i=1 \ldots N
\end{array}
$$

$W=\sum_{i=1}^{N} P R_{i}$

$$
p_{i} \geq C_{S P} \quad \forall i=1 \ldots . . N
$$

$$
P R_{i} \geq 0 \text { and are integers } \quad \forall i=1 \ldots . N
$$

The following numerical example is illustrated to validate the model.

\section{Numerical Analysis}

All the above discussed sub cases are illustrated in this section. Models have been solved with the same parameters and results are summarized in Table 1 and Table 2 for a completely coordinated VMI scenario and less coordinated VMI scenario respectively. To solve the problems formulated in all the sub cases, the software Lingo has been used. In case of a completely coordinated VMI scenario, the revenuesharing contract encourages buyers to order more units on premium payment and the vendor to extend his capacity. It works on complete coordination and correct information sharing between the vendor and buyers. The less coordinated VMI scenario is one where there is no contract price. The vendor sells the item at some selling price $C_{S P}$, to book his profit at his own end. Here also the inventory carrying 
cost and ordering cost of the buyer is born by the vendor. In this scenario, two situations may arise. 1) Vendor books his entire profit through his own revenue and does not share anything from the buyer's revenue. In this case $\theta_{i}=0 \quad \forall i=1 \ldots N$. 2) Vendor earns some profit by setting his selling price higher than the contract price and some by sharing the revenue of buyers. In this case $\theta_{i} \neq 0 \quad \forall i=1 \ldots . . N$.

\section{Example}

Consider a supply chain consisting of a single vendor and three buyers with the following parameters.

$N=3, d_{1}=3950$ units, $d_{2}=2800$ units, $d_{3}=1975, b_{1}=4, b_{2}=3, b_{3}=2.5$,

$C=30$ \$/units, $C_{W}=39 \$ /$ units, $h_{S}=1 \$ /$ unit, $h_{R 1}=1.5 \$ /$ unit, $h_{R 2}=1.5$

\$/unit, $h_{R 3}=1.5 \$$ /unit, $\alpha=0.20, \beta=0.30, \theta_{1}=0.5, \theta_{2}=0.5, \theta_{3}=0.5$, $S_{1}=75 \$$ /order, $S_{2}=75 \$$ /order, $S_{3}=75 \$$ /order, $S=300 \$$ /order, $K=550$ units. Now using equation (2), (3), and (4) we get.

$m=5, a_{1}=790$ units, $a_{2}=560$ units, $a_{3}=395$ units

Table 1 shows the values of all the parameters at $\theta_{i}=0.5 \forall i=1 \ldots .3$. Here it is considered that vendor and buyers are sharing revenue in equal proportions. The total amount of revenue is generated at the buyer's end and transparently with mutual consent is shared among the vendor and buyers. Such a transparent scenario improves coordination and helps in reducing the bullwhip effect.

\section{Observations}

- From Table 1, it is evident that the profit in the capacity extension sub case (1.2, 2.2) i.e. $(53896.49,53383.48)$ is more as compared to their corresponding without capacity extension sub case $(1.1,2.1)$, i.e. $(52081.48,48678.9)$. It proves that premium payment is in favor of the supply chain. It increases the profits of the vendor as well as buyers. Hence, it adds value to the supply chain. Moreover, on comparing the results of sub cases 1.2 and 2.2, it can be inferred that rationing reduces profit. It is because if rationing allocates more than optimal demand for some of the buyers, then the rest of the buyers had to buy more units on premium payment, which would compromise their profits. For example, buyer 3 is getting 183 units on rationing, whereas the optimal number of units for buyer 3 is 147. It means buyer 3 is getting 36 more units than his optimal demand. As a result. buyer 1 and buyer 2 had to order 36 more units on premium payment. It is clearly visible from Table 1 . In sub case 1.2 , the value of $\mathrm{W}=131$ units which become 167 units i.e., increases by 36 units in sub case 2.2. Moreover, the selling price of buyer 3 also reduces from $99.2 \$$ to $84.8 \$$ because of excess allocation. Hence, the buyer who is getting more than optimal demand, his profit also gets reduced because of a substantial reduction in his selling price (due to price-sensitive demand). In a nutshell, rationing causes drifting from optimality and reduces profit, and increases the bullwhip effect. 
Table 1 Comparative Result for all Cases for Completely Coordinated VMI Scenario (All Profits are for one Cycle)

\begin{tabular}{|c|c|c|c|c|}
\hline \multirow[b]{2}{*}{ Parameters } & \multicolumn{2}{|c|}{ Case 1} & \multicolumn{2}{|c|}{ Case 2} \\
\hline & Sub case 1.1 & Sub case 1.2 & Sub case 2.1 & Sub case 2.2 \\
\hline Total Supply Chain Profit (\$) & 52081.48 & 53896.49 & 48678.9 & 53383.48 \\
\hline Vendor's Profit (\$) & 26041.16 & 26947.99 & 24339.54 & 26691.49 \\
\hline $1^{\text {st }}$ Buyer's Profit (\$) & 13020.58 & 13216.5 & 10975.18 & 13147.8 \\
\hline $2^{\text {nd }}$ Buyer's Profit (\$) & 8466.125 & 8829.55 & 8551.78 & 8764.228 \\
\hline $3^{\text {rd }}$ Buyer's Profit (\$) & 4553.618 & 4902.45 & 4812.5 & 4779.96 \\
\hline All buyer' profit (\$) & 26040.32 & 26948.5 & 24339.46 & 26691.99 \\
\hline$C_{p}(\$)$ & 32.21 & 32.50 & 32.21 & 32.56 \\
\hline$p_{1}(\$)$ & 132.75 & 119 & 151.5 & 119 \\
\hline$p_{2}(\$)$ & 127.33 & 113.33 & 125.67 & 113.33 \\
\hline$p_{3}(\$)$ & 112.8 & 99.2 & 84.8 & 84.8 \\
\hline$P R_{1}$ (units) & - & 112 & - & 130 \\
\hline$P R_{2}$ (units) & - & 19 & - & 37 \\
\hline$P R_{3}$ (units) & - & $\mathbf{0}$ & - & $\mathbf{0}$ \\
\hline$D_{1}$ (units) & 259 & 314 & 184 & 314 \\
\hline$D_{2}$ (units) & 178 & 220 & 183 & 220 \\
\hline$D_{3}$ (units) & 113 & 147 & 183 & 183 \\
\hline W (units) & - & 131 & - & 167 \\
\hline
\end{tabular}

- Out of the aforementioned two cases, Case 1 i.e. selling price as an independent decision variable is always beneficial as compared to demand as an independent decision variable. It can be witnessed by observing the profits of the vendor and buyers from Table 1, i.e. (52081.48, 53896.49) is greater than (48678.9, 53383.48) respectively. The reason being while selling price is considered as an independent decision variable, it follows the optimal pricing policy and avoids rationing. Whereas in the case of demand as an independent decision variable, rationing comes into the picture because of limited capacity and provides the 
scope for the bullwhip effect. Moreover, it is not following the optimal pricing policy. Hence profits too reduce.

- Because of revenue sharing contract, buyers are motivated to sell more units, which they are buying on premium payment because of scarce supply. Premium payment motivates the vendor to produce more quantity. This scenario increases coordination between the vendor and buyers and reduces the bullwhip effect.

Further, in case of a completely coordinated VMI scenario, the vendor is getting the desired share because of the revenue-sharing contract, hence motivated for contract price and capacity extension. But in less coordinated VMI scenario, as buyer's selling price is very high and most of the expenses are met by the vendor, the vendor will also try to sell his product at higher $C_{S P}$. As a result, buyer's selling price would increase. Since demand at the buyer's end is price sensitive, demand will fall and buyers won't buy premium unit. In this scenario, both parties the vendor and buyers, are making decisions in isolation for their own benefits. This noncooperative behavior promotes the bullwhip effect. An increase in $C_{S P}$ would increase non-coordination and hence bullwhip effect. The maximum possible value of $C_{S P}$, till which all sub cases would remain feasible, is $84.8 \$$. Beyond this value,

Case 2 becomes infeasible; hence we have calculated all the parameters for less coordinated VMI scenario at $C_{S P}=84.8 \$$.

Table 2 Comparative Result for all cases for Less Coordinate Model at CSP $=84.8 \$^{*}$ All the Profits Shown are for one Cycle

\begin{tabular}{|l|c|c|c|c|}
\hline & \multicolumn{2}{|c|}{ Case 1 } & \multicolumn{2}{c|}{ Case 2 } \\
\hline \multicolumn{1}{|c|}{ Parameters } & Sub case 1.1 & Sub case 1.2 & Sub case 2.1 & Sub case 2.2 \\
\hline Total Supply Chain Profit (\$) & 48422.6 & $\mathbf{5 2 0 8 1 . 4 8}$ & 48678.9 & $\mathbf{4 9 1 2 3 . 4}$ \\
\hline Vendor's Profit (\$) & 24589.95 & 28927.5 & 28927.5 & 29358.07 \\
\hline $1^{\text {st }}$ Buyer's Profit (\$) & 12701.25 & 12419.35 & 12272.8 & 12286.73 \\
\hline $2^{\text {nd }}$ Buyer's Profit (\$) & 7782.6 & 7570.63 & 7478.6 & 7479.21 \\
\hline $3^{\text {rd }}$ Buyer's Profit (\$) & 3348.8 & 3164 & 0 & 0 \\
\hline All buyer' profit (\$) & 23832.65 & 23153.98 & 19751.40 & 19765.33 \\
\hline$p_{1}(\$)$ & 141.25 & 132.75 & 151.5 & 149.75 \\
\hline$p_{2}(\$)$ & 135.67 & 127.33 & 125.67 & 125.67 \\
\hline$p_{3}(\$)$ & 121.6 & 112.8 & 84.8 & 84.8 \\
\hline
\end{tabular}




\begin{tabular}{|l|c|c|c|c|}
\hline$P R_{1}$ (units) & - & $\mathbf{0}$ & - & $\mathbf{7}$ \\
\hline$P R_{2}$ (units) & - & $\mathbf{0}$ & - & $\mathbf{0}$ \\
\hline$P R_{3}$ (units) & - & $\mathbf{0}$ & - & $\mathbf{0}$ \\
\hline$D_{1}$ (units) & 225 & 259 & 184 & 191 \\
\hline$D_{2}$ (units) & 153 & 178 & 183 & 183 \\
\hline$D_{3}$ (units) & 91 & 113 & 183 & 183 \\
\hline W (units) & - & $\mathbf{0}$ & - & 7 \\
\hline
\end{tabular}

On comparing the results of Table 1 and Table 2, the following inferences can be generated

In the less coordinated VMI scenario (Table 2), the vendor and buyers perform business operations in their individual benefits. The vendor decides his selling price on his own to get his desired share. As the vendor increases his selling price, to increase his profit, it impacts total supply chain profit adversely for all the cases. For example, at $C_{S P}=84.8 \$$, the maximum value of total supply chain profit is $52081.48 \$$, which is less than the corresponding value $(53896.49 \$)$ of a completely coordinated VMI scenario.

In less coordinated VMI scenario, a higher value of $C_{S P}$ discourages buyers to put the demand of premium units. For example, at $C_{S P}=84.8 \$$, the value of $\mathrm{W}$ falls to 0 from 131 and to 7 from 167 in sub cases 1.2 and sub case 2.2 respectively. Moreover, such a condition motivates the vendor to fluctuate the value of $C_{S P}$ from one cycle to another. This fluctuation results in fluctuation in demand and hence would increase the bullwhip effect.

A completely coordinated VMI scenario helps in sharing accurate information of sales with the vendor as compared to less coordinated VMI scenario. It circumvents the distortion of information and hence reduces the bullwhip effect.

The revenue-sharing contract of the completely coordinated VMI scenario lures the buyers to order more and more premium units. It assures the vendor to have the desired profit and promotes him to set the contract price as low as possible. Lower contract price increases coordination and reduces the bullwhip effect.

Figure 2, Figure 3 and Figure 4 respectively, show the impact of $C_{S P}$ on the supply chain, in terms of supply chain profit, buyer's selling price and vendor's profit. 


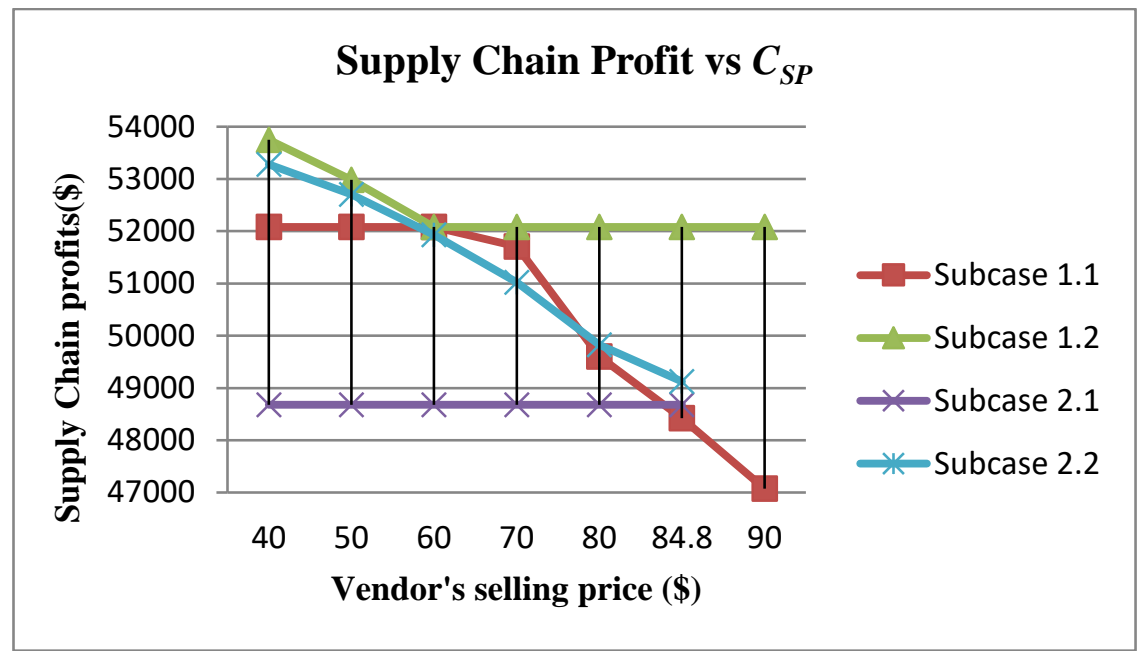

Figure 2 Supply Chain Profit vs. vendors Selling Price $\left(\boldsymbol{C}_{S P}\right)$

Figure 2 shows that the supply chain gains maximum profit in sub case 1.2 in less coordinated VMI scenario like the completely coordinated VMI scenario. But in this case, as the vendor's selling price increases supply chain profit decreases. It is most affected in capacity extension cases. It shows that the vendor's higher selling price discourages buyers from paying the premium payment. On the other hand, vendor's lower selling price encourage the buyers for paying premium payment for extra units. This will cause a fluctuation in the number of premium units and hence will cause fluctuation in demand from one cycle to another. This behavior of demand pattern is responsible for the bullwhip effect.

$$
p_{i} \text { vs } C_{S P}
$$

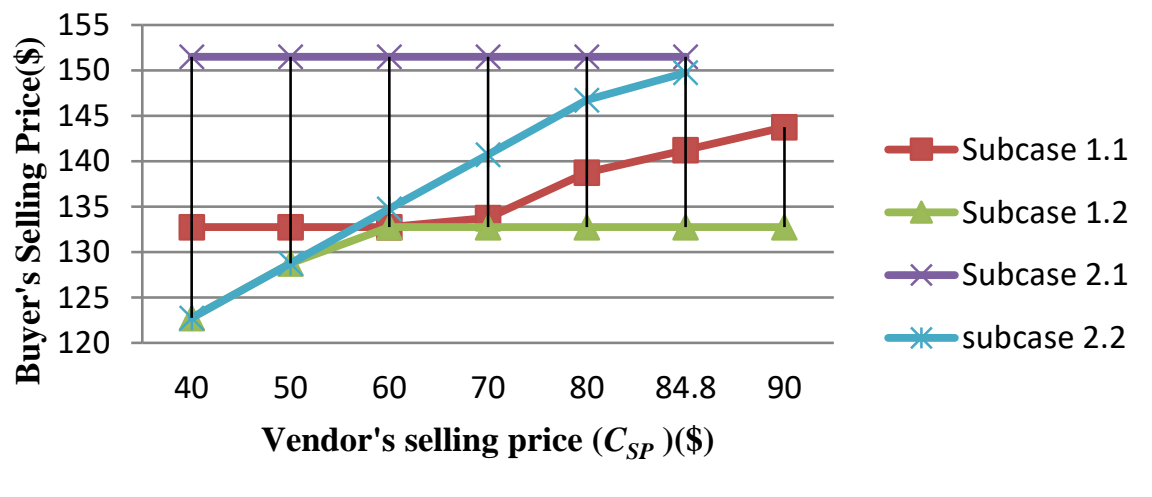

Figure 3 Buyer's Selling Price vs. vendor's Selling Price $\left(\boldsymbol{C}_{S P}\right)$

Figure 3 shows that in case of less coordinated VMI scenario, as the vendor's selling price increases buyer's selling price also increases. Since buyer's are dealing with price-sensitive demand, it would cause a reduction in demand. Fluctuation in 
$C_{S P}$ from one cycle to another will cause fluctuation in demand and hence would cause the bullwhip effect.

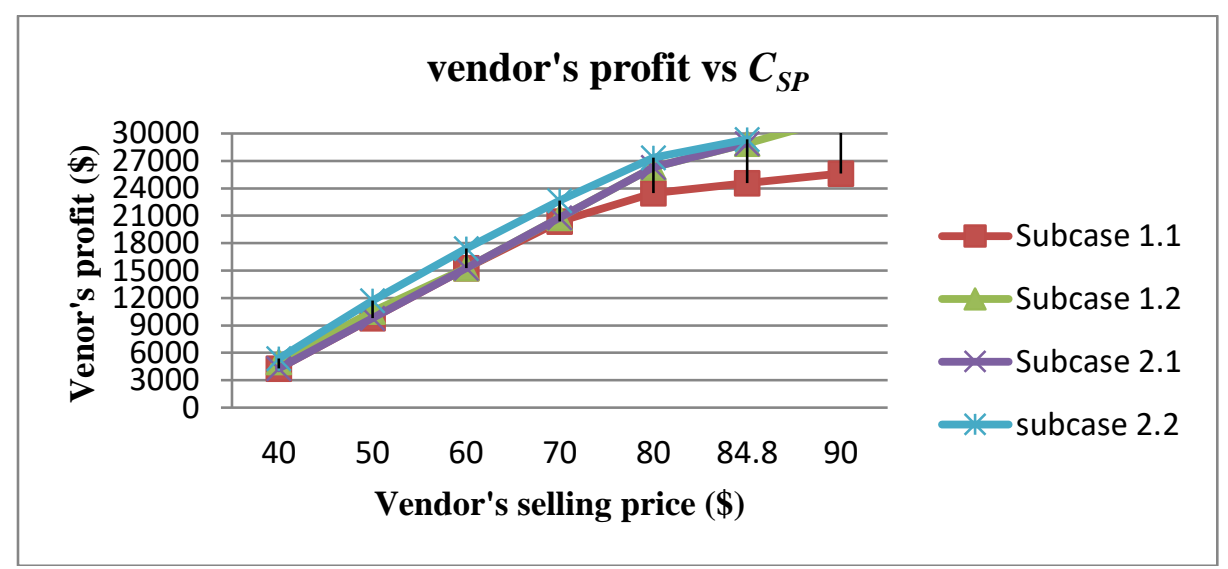

Figure 4 Vendor's Profit vs. Vendor's Selling Price (CSP).

Though, it can be inferred from Figure 4 that, as the vendor increases the selling price of the item $\left(\boldsymbol{C}_{\boldsymbol{S P}}\right)$ his profit increases, yet the total supply chain profit starts falling as can be seen by Figure 2. The reason being, increase in $C_{S P}$ discourages buyers to put the demand for premium units. For example, buyer $1 \&$ buyer 2 who were placing an order of 112 premium units and 19 premium units at contract price are not willing to place any order of premium unit at $\boldsymbol{C}_{\boldsymbol{S} \boldsymbol{P}}=84.8 \$$. Moreover, there does not exist any value of $\mathrm{C}_{\mathrm{SP}}$ for which, less coordinated VMI scenario has more supply chain profit as compared to the completely coordinated VMI scenario corresponding to any sub case. Since in less coordinated VMI scenario each member is thinking in isolation about his own profit only, it results in the bullwhip effect. Such behavior may encourage the vendor to change his selling price from cycle to cycle and price variation is a big cause of the bullwhip effect.

\section{Managerial Insight}

The discussed model provides many useful implications from the managerial point of view. In the case of scarce supply, the concept of VMI and revenue-sharing must be applied. VMI eliminates the chances of manipulation of demand by buyers and mitigates the bullwhip effect. Further, the revenue-sharing contract motivates buyers to work efficiently to promote sales. It reduces the bullwhip effect by increasing coordination and transparency among different members of the supply chain. THE revenue-sharing VMI model is more coordinated as compared to the without revenue-sharing VMI model and hence revenue- sharing contract helps in reducing the bullwhip effect. In case of limited supply and price-sensitive demand, allocation of supply corresponding to optimal price is a better decision as compared to rationing. Rationing induces a bullwhip effect and reduces profit. The proposed model helps in deciding about contract price between buyer and vendor, Vendor's capacity extension, the selling price of the buyers, and the number of units for which each buyer should pay the premium. 


\section{Conclusion \& Future Scope}

In literature, (Chen et al., 2000 and Dejonckheere et al., 2004) it had been shown that better information sharing reduces the bullwhip effect. The same has been proved in the present paper numerically, by comparing a completely coordinated VMI scenario with less coordinated VMI scenario. In this paper, mathematical models for a monopolistic environment consisting of limited capacitated vendor and multiple buyers with and without contract price are formulated. It has been proved that a completely coordinated VMI scenario turns the competition between vendor and buyer into a joint venture, where both fight for a common objective. VMI helps in dealing with the bullwhip effect as it makes information sharing fast and correct. It reduces the number of echelons between the vendor and end consumer and increases coordination between them and hence reduces the bullwhip effect significantly. The revenue-sharing contract further increases coordination between different players of the supply chain. To show the impact of revenue sharing, results of a completely coordinated VMI model and less coordinated VMI model are compared and it has been proved that contract price and revenue sharing jointly increases coordination and reduces bullwhip effect whereas vendor's selling price reduces the coordination and supply chain profit and increases bullwhip effect. Through modeling, it has been proved that a premium payment scheme helps the supply chain to improve total supply chain profits and hence individual profits.

The proposed model is different from models discussed in the literature as none of the previous literature considered premium payment, rationing, revenue-sharing contract, and VMI in a single model. The results obtained are very significant as it reduces bullwhip effect without compromising on optimality under the aforementioned scenario. It would be interesting future work to extend the model for deteriorated items. Idea of inflation can also be introduced to get the present worth of money. Models can be extended for multi-item and multiple suppliers.

\section{References}

1. Adnan, Z. H., and Ozelkan, E. (2020), "Bullwhip Effect in Pricing under the Revenue-sharing Contract", Computers \& Industrial Engineering, Vol. 145, https://doi.org/10.1016/j.cie.2020.106528.

2. Agrawal, S., Sengupta, R.N. Shanker, K. (2009), "Impact of information sharing and lead time on bullwhip effect and on-hand inventory", European Journal of Operational Research, Vol.192, pp. 576-593.

3. Cachon, G.P. and Lariviere, M.A. (1999(a)), "An equilibrium analysis of the linear, proportional and uniform allocation of scarce capacity", IIE Transactions, Vol. 31 (No. 9), pp. 835-849.

4. Cachon, G.P. and Lariviere, M.A. (1999b), "Capacity choice and allocation: Strategic behavior and supply chain performance", Management Science, Vol. 45 (No. 8), pp.1091-1108.

5. Chatfield D.C., Kim J.G., Harrison T.P., Hayya J.C. (2004), "The bullwhip effect - Impact of stochastic lead time, information quality, and information 
sharing: A simulation study", Production and Operations Management, Vol. 13 (No. 4), pp. 340-353.

6. Chen, F., Z. Drezner, J. K. Ryan, D. Simchi-Levi. (2000), "Quantifying the Bullwhip Effect in a simple supply chain: The impact of forecasting, lead times, and information", Management Science, Vol. 46(No. 3), pp. 436-443.

7. Chen, L., Chen, X., Keblis, M.F. and Li, G. (2019), "Optimal pricing and replenishment policy for deteriorating inventory under stock-level-dependent, time-varying and price-dependent demand", Computers\& Industrial Engineering, Vol. 135, pp.1294-1299.

8. Darwish, M.A \& Odah, O.M. (2010), "Vendor managed inventory model for single-vendor multi-buyer supply chains", European Journal of Operational Research, Vol. 204, pp. 473-484.

9. Daugherty, Patricia J., Matthew B. Myers, and Chad W. A. (1999), "Automatic Replenishment Programs: An Empirical Examination," Journal of Business Logistics, Vol. 20(No. 2), pp. 63-82.

10. Dejonckheere, J., Disney, S. M., LambrechtM. R., Towill, D. R. (2004), “The impact of information enrichment on the Bullwhip Effect in supply chains: A control theoretic approach", European Journal of Operations Research, Vol. 153(No. 3), pp. 727-750.

11. Deshpande V. and Schwarz, L.B. (2002), "Optimal capacity choice and allocation in decentralized supply chains", work paper, Krannert School of Management, Purdue University, West Lafayette, Indiana, USA.

12. Disney, S.M. and Towill, D.R. (2003) "Vendor-managed inventory and bullwhip reduction in a two-level supply chain", International Journal of Production and Operations Management, Vol. 23(No. 6), pp. 625-651. ISSN: 0144-3577. DOI: 10.1108/01443570310476654.

13. Forrester, J.W. (1961), Industrial Dynamics, Cambridge M.A., MIT Press, Cambridge.

14. Jaggi, C.K., Aggarwal, K. K. and Verma, M. (2010) "Allocation Game in a single period supply chain model”, Revista Investigacion Operacional, Vol. 31 (No. 3), pp. 258-267.

15. Jaggi, C. K., Jain, R. and Verma, M. (2018 (a)), "Quantitative analysis for Measuring and suppressing bullwhip effect", Yugoslav Journal of Operations Research, Vol. 28 (No. 3), pp. 415-433.

16. Jaggi, C. K., Jain, R. and Verma, M. (2018 (b)), "Impact of demonetization on Supply Chain in Indian Context", AIMS, International, Journal of Management, Vol.12 (No.1), pp.1-10.

17. Jain, R., Verma, M., and Jaggi, C. K. (2020), "Impact on bullwhip effect in food industry due to food delivery apps", OPSEARCH, pp. 1-12.

18. Kaplan, A. (1969), "Stock Rationing", IIE Management Science, Vol.15, pp. 5260-267.

19. Kim, J., Hong, Y. and Kim, T. (2011), "Pricing and ordering policies for pricedependent demand in a supply chain of a single buyer and a single manufacturer”, International Journal of System Science, Vol. 42(No. 1), pp. 8189.

20. Lee, H. Padmanabhan P. and Whang, S. (1997 (a)), "The Bullwhip effect in supply chains", Sloan Management Review, Vol. 38, pp. 93-102. 
21. Lee, H. Padmanabhan P. and. Whang, S. (1997 (b)), "Information distortion in a supply chain: The bullwhip effect", Management Science, Vol. 43, pp. 546-558.

22. Osborne, M. J. (2007). Mathematical methods for economic theory: a tutorial. University of Toronto, Toronto.

23. Özelkan, E, C. and Çakanyıldırım, M. (2008), "Reverse bullwhip effect in pricing", European Journal of Operational Research, Vol. 192(No. 1), pp. 302312.

24. Tai, P. D., Duc, T. T. H., and Buddhakulsomsiri, J. (2019), "Measure of bullwhip effect in supply chain with price-sensitive and correlated demand", Computers \& Industrial Engineering, Vol. 127, pp. 408-419.

25. Yang, J. and Yang, S. (2007), "The use of a premium-payment scheme in a supply chain involving capacity acquisition", European Journal of Operational Research, Vol. 181, pp.207-223.

\section{Appendix 1}

The concavity of NLPP P1 can be proved by proving necessary and sufficient condition of following theorem.

Theorem 1: In case of multivariable nonlinear objective function subject to linear constraints, if Hessian matrix of objective function is negative definite (semi definite) then function possesses local (global) maxima of objective function at stationary point. (Osborne, 2007).

Proof: For N+1variables, Hessian matrix of model represented by $\mathrm{P} 1$ can be expressed by $\mathrm{H}$.

$$
H=\left(\begin{array}{cccccc}
-2 b_{1} & 0 & 0 & - & 0 & b_{1} \\
0 & -2 b_{2} & 0 & - & 0 & b_{2} \\
0 & 0 & -2 b_{3} & - & 0 & b_{3} \\
\mid & 0 & 0 & & & \mid \\
0 & 0 & 0 & & -2 b_{N} & b_{N} \\
b_{1} & b_{2} & b_{3} & - & b_{N} & 0
\end{array}\right)
$$

All Eigen values of $\mathrm{H}$ would be either $-b_{i}$ or 0 , as $b_{i}>0$, for all $i=1,2 \ldots \mathrm{N}$. Hence, all Eigen values would be negative or zero.

Therefore, joint profit function $\sum_{i=1}^{N} \pi_{r i}\left(p_{1}, p_{2}, \ldots, p_{N}, C_{p}\right)$ represented by P1 would be negative semi definite. Hence Case 1.1 would possess global maxima.

\section{Appendix 2}

The optimality of any NLPP can be proved through KKT conditions.

Hence, KKT conditions for NLPP P2 can be written as 


$$
\begin{aligned}
& a_{i}-2 b_{i} p_{i}+C_{p} b_{i}+\mu_{i}+\lambda_{1} b_{i}=0 \quad \forall i=1 \ldots N \\
& -\sum_{i=1}^{N}\left(\left(a_{i}-b_{i} p_{i}\right)+\alpha P R_{i}\right)+\lambda_{1}-\left(\sum_{i=1}^{N} \mu_{i}\right)=0 \\
& -\alpha C_{p}+\lambda_{2}-\lambda_{1}\left(\frac{K\left(C_{w}-C\right)-S^{*}}{(K+W)^{2}}-\frac{\sum_{i=1}^{N}\left(h_{R i} D_{i}\left(p_{i}\right)\right)}{2(K+W)^{2}}\right)=0 \\
& \frac{K C+C_{W} W+S^{*}}{K+W}+h^{*}-C_{p} \leq 0, \lambda_{1} \geq 0 \text { and } \lambda_{1}\left(\frac{K C+C_{W} W+S^{*}}{K+W}+h^{*}-C_{p}\right)=0 \\
& \text { Where } h^{*}=\frac{h_{s} *(K+W)+\sum_{i=1}^{N}\left(h_{R i} D_{i}\left(p_{i}\right)\right)}{2(K+W)} \text { and } S^{*}=S+\sum_{i=1}^{N} S_{i} \\
& \sum_{i=1}^{N}\left(a_{i}-b_{i} p_{i}-P R_{i}\right)-K \leq 0, \lambda_{2} \geq 0 \text { and } \lambda_{2}\left(\sum_{i=1}^{N}\left(a_{i}-b_{i} p_{i}-P R_{i}\right)-K_{i}\right)=0 \\
& \left.C_{p}-p_{i} \leq \mu_{i} \geq 0 \text { and } \mu_{i}\right)=0 \quad \forall i=1 \ldots N
\end{aligned}
$$

The above system of inequality is difficult to solve mathematically, but the solution of P2 given in Table 1, sub case 1.2 satisfies the above system. Hence is sufficient to prove its optimality (Osborne, 2007).

\section{Appendix 3}

KKT conditions for NLPP P4 can be written as

$$
\begin{aligned}
& a_{i}-2 b_{i} p_{i}+C_{p} b_{i}+\mu_{i}+\lambda_{1} b_{i}=0 \quad \forall i=1 \ldots N \\
& -\sum_{i=1}^{N}\left(\left(a_{i}-b_{i} p_{i}\right)+\alpha P R_{i}\right)+\lambda_{1}-\left(\sum_{i=1}^{N} \mu_{i}\right)=0 \\
& -\alpha C_{p}+\lambda_{2}-\lambda_{1}\left(\frac{K\left(C_{w}-C\right)-S^{*}}{(K+W)^{2}}-\frac{\sum_{i=1}^{N}\left(h_{R i} D_{i}\left(p_{i}\right)\right)}{2(K+W)^{2}}\right)=0 \\
& \frac{K C+C_{W} W+S^{*}}{K+W}+h^{*}-C_{p} \leq 0, \lambda_{1} \geq 0 \text { and } \lambda_{1}\left(\frac{K C+C_{W} W+S^{*}}{K+W}+h^{*}-C_{p}\right)=0
\end{aligned}
$$




$$
\begin{aligned}
& \text { Where } h^{*}=\frac{h_{s} *(K+W)+\sum_{i=1}^{N}\left(h_{R i} D_{i}\left(p_{i}\right)\right)}{2(K+W)} \text { and } S^{*}=S+\sum_{i=1}^{N} S_{i} \\
& \sum_{i=1}^{N}\left(a_{i}-b_{i} p_{i}-P R_{i}\right)-K \leq 0, \lambda_{2} \geq 0 \text { and } \lambda_{2}\left(\sum_{i=1}^{N}\left(a_{i}-b_{i} p_{i}-P R_{i}\right)-K\right)=0 \\
& C_{p}-p_{i} \leq 0, \mu_{i} \geq 0 \text { and } \quad \mu_{i}\left(C_{p}-p_{i}\right)=0 \quad \forall i=1 \ldots N
\end{aligned}
$$

The above system of inequality is difficult to solve mathematically, but the solution of P4 given in Table 1, sub case 2.2 satisfies the above system. Hence is sufficient to prove its optimality (Osborne, 2007).

\section{About Our Authors}

Reena Jain is research scholar in Department of Operational Research, University of Delhi and is working as an assistant professor in Kalindi College, University of Delhi. She has earned dual masters, one in Operational Research and the other in Mathematics. Her research interest lies in the field of Inventory Management and Supply Chain Management. She has published papers in proceedings of ICPQROM and International Journal of Strategic Decision Sciences, YUJOR, AIMS, OPSEARCH, IJSOI etc. She has published one chapter also in a book "Analytical Approaches to Strategic Decision Making Interdisciplinary consideration” published by IGI global.

Chandra K. Jaggi, Professor and former Head, Department of Operational Research, University of Delhi, is a recipient of the Amity Academic Excellence Award in February 2019 by Amity University and was honoured with International Best Researcher Award 2017 by the International Science Community Association at Bhutan. He was awarded "IEOM Outstanding Service Award" by IEOM Society, USA in 2016. Associate Editor of OPSEARCH and IJSAEM, Springer and on the editorial board of the IJSS: Operations \& Logistics, IJSOI, and AJOR. He is the most active author in the topic Inventory \& Supply Chain Management He has published more than 150 papers.

Mona Verma is working as an assistant professor in Shaheed Sukhdev College of Business Studies, University of Delhi. Her research interest lies in the field of Inventory Management and Supply Chain Management. She has publications in many international journals like Revista Investigacion Operacional (Cuba), YUJOR, International journal of Applied Operations Management, International Journal of Logistics and Supply Chain Management, International Journal of Industrial and System Engineering, OPSEARCH, IJORO, IJSOI and Applied Mathematics and Computation. She has attended many national as well as international conferences. 